\title{
PERSPECTIVAS MUNDIAIS DA AVALIAÇÃO NA EDUCAÇÃO SUPERIOR
}

\author{
WORLD PERSPECTIVES OF EVALUATION
}

IN HIGHER EDUCATION

\section{PERSPECTIVAS MUNDIALES DE LA EVALUACIÓN EN LA EDUCACIÓN SUPERIOR}

TAUCHEN, G.; FÁVERO, A. (Orgs.). Avaliação do ensino superior: perspectivas mundiais. Curitiba: CRV, 2017.

Lidiane Limana Puiati Pagliarin ${ }^{\mathrm{I}}$

I Universidade Federal da Fronteira Sul, Rio Grande do Sul - Brasil. E-mail: lidiane.puiati@uffs.edu.br. ORCID: http://orcid.org/0000-0002-5390-5167

A discussão sobre o tema avaliação sempre é pertinente, pois, mesmo sendo um campo de conflitos e tensões, é consenso entre os estudiosos de que avaliar é muito importante para acompanhar os resultados de práticas que vêm sendo desenvolvidas em um determinado contexto. Em se tratando de educação superior, a avaliação torna-se relevante em 
decorrência das reformas políticas e administrativas realizadas por diferentes países nos últimos anos, principalmente no que tange à expansão da mesma. Nesse sentido, com o objetivo de oportunizar ao leitor o conhecimento de experiências de avaliação da educação superior desenvolvidas em países da América, da Europa e da África, é que Gionara Tauchen e Altair Alberto Fávero organizaram o livro "Avaliação do Ensino Superior: perspectivas mundiais".

Tal obra nasce de duas redes internacionais de estudos e pesquisas: Grupo de Trabalho CLACSO (Consejo Latinoamericano de Ciencias Sociales) Universidades e Políticas de Educação Superior e REDES (Rede de Estudos e Pesquisas em Educação Superior), das quais os organizadores participam ativamente: Tauchen que, além de coordenadora da REDES, representa a Universidade Federal de Rio Grande, e Fávero, pesquisador da REDES e representante da Universidade de Passo Fundo. O livro que inaugura a Coleção "Avaliação do Ensino Superior", da Editora CRV, foi lançado em 2017. Num total de 200 páginas, conta com dez capítulos escritos por autores nacionais e internacionais de diversas instituições que discutem a avaliação da educação superior mediante diferentes perspectivas, narrando experiências em avaliação desenvolvidas em seus países. O coordenador do Grupo de Trabalho CLACSO, António Teodoro, é quem assina o prefácio do livro.

O capítulo que abre a discussão do livro, de autoria de Gionara Tauchen, é intitulado “Avaliação da educação superior: dinâmicas, regulações e transformações". Neste texto, a autora afirma haver consenso da necessidade de se avaliar a qualidade tanto do ensino quanto de cursos e de instituições, especialmente os que se configuram como fruto da expansão da educação superior. Baseando-se em autores da literatura nacional e internacional, sustenta a tese de que a avaliação da educação superior, no contexto neoliberal, vem consolidando aliança entre Estado, organismos multilaterais e interesses econômicos, o que tem gerado tensões. Tauchen tece algumas críticas em relação à avaliação nesse nível de ensino, tais como: a avaliação externa tem sido o principal instrumento de regulação de políticas públicas por parte de agências de acreditação e de avaliação; nesse contexto, há uma tendência ao controle dos Estados que administram estratégias de desenvolvimento, definem e orientam, de forma centralizadora, a execução de políticas que se voltam à educação superior; as universidades, muitas vezes, empenham-se em atender critérios objetivos dessa avaliação, baseada em produtividade, em detrimento da qualidade de uma formação humana e científica; há uma defesa de que os resultados dessas avaliações sejam públicos e transparentes, no 
Pagliarin, L. L. P.

entanto, no caso brasileiro, podem ser acessados publicamente, mas a complexidade de organização desses dados dificulta e mascara a análise dos referidos resultados. Por fim, a autora estabelece relações entre a avaliação da educação superior no Brasil e em Cabo Verde e assevera que os sistemas de avaliação destes países possuem muita similaridade, indicando que a homogeneidade legal, via acordos de cooperação de países lusófonos, foi se transformando em homogeneidade de avaliação, constituindo-se em um modelo passível de transposição entre países.

Na sequência, o capítulo "O sistema de acreditação regional de cursos universitários do Mercosul (Sistema Arcu-Sur): percursos e desafios", de Gladys Barreyro e Gabriella Hizume, caracteriza inicialmente o Mercado Comum do Sul - Mercosul. De acordo com as autoras, o tratado foi assinado em 1991, com o objetivo de inserir os Estados do Cone Sul da América do Sul no competitivo mercado internacional. Mesmo sem a área educacional ter sido contemplada explicitamente no tratado, os Ministros de Educação dos Estados-membros encaminharam Protocolo de Intenções, devidamente aceito pelo Conselho pertinente. A partir disso, criou-se um fórum para debate de questões relacionadas ao reconhecimento de título universitário, aos procedimentos de avaliação e à acreditação de cursos de graduação, entre outros temas relevantes da educação superior. Após alguns entraves, em 2008, é criado o Sistema Arcu-Sul, cujo objetivo é a acreditação de cursos de graduação universitária e a circulação de trabalhadores diplomados entre países do Mercosul e dos Estados Associados. As autoras finalizam o capítulo, indicando impasses, ajustes e avanços do referido sistema, dentre os quais se destacam: falta de estrutura e descompasso entre manifestação de vontade e exequibilidade; ajustes - afinar os mecanismos de acreditação do curso às legislações nacionais de autorização de exercício profissional; e avanços - disseminação da cultura de avaliação e acreditação como formas de controle da qualidade da educação superior e empenho dos Ministérios da Educação de diferentes países para elaboração do próprio sistema.

O terceiro capítulo, elaborado por Alejandra López e José Llavador, intitula-se "Rankings en educación superior: reflexiones y escenarios de la calidad educativa". O texto discute a avaliação da educação superior na Espanha, apresentando a Agência Nacional de Avaliação da Qualidade e Acreditação como órgão responsável pela avaliação, certificação e acreditação do ensino, do corpo docente e das instituições deste país. Além de diversos programas de avaliação da educação, a Espanha criou, em 2013, os Indicadores Sintéticos das 
Universidades Espanholas, os quais disponibilizam rankings com informações detalhadas sobre as universidades. Analisando diferentes metodologias utilizadas para o ranqueamento das mesmas, os autores admitem que tal classificação possui instrumento legítimo e utilidade em muitas situações, todavia os rankings simplificam a realidade ao indicar a melhor universidade sem levar em consideração os diversos fatores que estruturam cada instituição como, por exemplo, a extensão da universidade, o percentual de docentes, o investimento em recursos, entre outros. Por conseguinte, os autores defendem a necessidade do desenvolvimento de instrumentos de avaliação nacional, tendo em vista a análise e a combinação de dados dos rankings nacionais com os internacionais, sem deixar de atender às especificidades das instituições.

O capítulo seguinte, intitulado "Construção do Espaço Europeu de Ensino Superior: os sistemas de avaliação e a profissão acadêmica em Portugal e Espanha", produzido por Carla Galego e Célia Pires, relata o trabalho desenvolvido nestes dois países com o intuito de alcançar um dos objetivos da Declaração de Bolonha, isto é, o reforço da garantia de qualidade das instituições de educação superior europeias. A primeira ação equivale à construção do Espaço Europeu de Ensino Superior e, na sequência, cada Estado signatário desenvolveu sistemas de avaliação nacional, balizados por diretrizes comuns. As autoras apontam resultados dos sistemas de avaliação no exercício da profissão acadêmica dos dois países, a saber: os sistemas influenciam diretamente nos mecanismos de acesso e progressão da carreira docente, que não acontece mais de forma automática; precarização da profissão docente; os professores em início ou meio de carreira sentem-se pressionados a produzir cientificamente (em quantidade); valorização da pesquisa em detrimento do ensino. Com base em tais resultados, as autoras concluem ressaltando que, mesmo com modelos de avaliação diferentes, houve (re)configuração da profissão docente universitária em ambos os países.

Nessa perspectiva, o quinto capítulo denominado “Quién evalúa a la evaluación: los hilos que la estrangulan. Experiencias en académicos", escrito por Aristeo López, Tania Reynoso e Marisa Roman, também discorre sobre o professor universitário no cenário das avaliações de desempenho. Para tanto, os autores colocam em evidência uma caracterização dos professores no contexto mexicano, bem como discutem a forma como ocorre essa avaliação de desempenho docente. Ainda fazem forte crítica à forma de ingresso de professores na universidade, uma vez que há um clima de endogamia presente, ou seja, são admitidos os candidatos formados na mesma instituição, criando, com isso, corporativismo, 
Pagliarin, L. L. P.

nepotismo, etc. Após ingressarem, são pressionados em virtude da necessidade de produtividade científica, um dos aspectos da avaliação de desempenho, ou então, lhes é exigida a captação de recursos à universidade (capitalismo acadêmico). Não obstante, não são avaliados pela originalidade das pesquisas ou pelo impacto destas na sociedade, por exemplo. Ao finalizar o texto, defendem a revisão dos critérios para que a avaliação se torne menos fragmentada e mais transparente.

"La regulación de la institucionalidad, el financiamento y la calidad em el sistema de educación superior em Chile", escrito por Óscar Díaz e Luis González-Fiegehen, é o sexto capítulo do livro. O texto analisa o desenvolvimento dos mecanismos de regulação de carreiras e programas de pós-graduação na educação superior chilena nas últimas décadas. Tal análise é realizada diante da deferência à qualidade, à institucionalização e ao financiamento sob três níveis específicos: discurso, normas e execução. Em síntese, os autores argumentam que a participação do Estado é fraca e limitada, pois, além de não oferecer estrutura, carece de atribuições legais. Nesse sentido, movimentos estudantis têm pressionado o governo chileno para que mudanças ocorram no sistema de educação superior, especialmente em relação aos aspectos já mencionados: qualidade, institucionalização e financiamento. Por sua vez, o governo tem realizado alguns avanços, entretanto ainda há pontos a melhorar. Sob tal perspectiva, os autores encerram o texto, apresentando propostas de melhoria da educação superior no Chile.

O sétimo capítulo é escrito por Boris Pérez, Enrique Bajos e Yeny Brito e intitula-se "Evaluación de la educación superior en Cuba: desarrollo e impacto". O objetivo do texto corresponde à análise das diferentes etapas de desenvolvimento dos processos de avaliação da qualidade da educação superior cubana. Os autores reconhecem que a criação do Ministério da Educação Superior, em 1976, possibilitou, dentre outras ações, o estabelecimento de um sistema de avaliação externa que se aperfeiçoou com o passar dos anos até a década de 1990, quando ocorreram modificações substantivas. Antes focada em inspeção e verificação das normas, hoje a avaliação externa assume compromisso com a qualidade da formação em níveis de graduação e pós-graduação, pesquisa e extensão, assim como com o financiamento. Consoante aos autores, o sistema de avaliação atual é de 2011 e vem realizando a acreditação de cursos e instituições que cumpram com requisitos de qualidade. Com a criação da Junta de Acreditación Nacional, o referido sistema tem obtido 
resultados significativos à educação superior cubana, mesmo diante da necessidade de fortalecê-lo ainda mais e qualificar os que realizam as avaliações.

Na sequência, no oitavo capítulo "A avaliação no Subsistema do Ensino Superior em Angola: realidade \& desafios", Alfredo Buza e Juliana Caga analisam, de forma similar, o processo de avaliação da educação superior no contexto do Subsistema do Ensino Superior em Angola por meio de entrevistas, observações, análises documental e do discurso, bem como revisão bibliográfica. A coleta de dados ocorreu em quatro instituições de ensino superior, sendo uma privada e três públicas. Os autores ressaltam que são realizadas avaliações em três âmbitos no Subsistema: avaliação da aprendizagem, sendo a maioria de modelo tradicional; avaliação docente, com ações isoladas, sem parâmetros; avaliação institucional, que ainda não ocorre como um processo regular e sistemático, porém, mesmo com diferenças regionais, de infraestrutura e de recursos, apresenta o mesmo objetivo relativo à padronização e à harmonização. Sendo assim, em conformidade com os autores, o maior desafio é a criação de regulamentações claras à educação superior.

O penúltimo capítulo intitula-se "As reconfigurações do campo académico em Portugal: perspectivas emergentes da avaliação das Unidades de Investigação e Desenvolvimento entre 1994 e 2016" e tem como autoria Mariana Alves e Camila Lopes. O objetivo do texto é o de caracterizar as reconfigurações no campo acadêmico da educação superior portuguesa no respectivo período. Tal recorte temporal se deve ao fato de que, em 1994, foram criadas as Unidades de Investigação e Desenvolvimento, responsáveis pela avaliação institucional da educação superior no país. Com base na leitura de documentos, relatórios e microdados sobre essas avaliações, as autoras afirmam que as Unidades surgiram para contrapor o atraso científico português nas diversas áreas comparativamente aos parâmetros internacionais. Nas últimas décadas, houve um acentuado crescimento da produção científica, bem como formação de novos doutores e internacionalização; tudo acompanhado pelo crescimento das próprias Unidades ao mesmo tempo em que se determina um desafio: consolidar esse sistema científico e investir em recursos e condições à pesquisa, já que hoje somente as Unidades bem avaliadas recebem financiamento da Fundação. Ao concluir o texto, as autoras enfatizam que as Unidades de Investigação e Desenvolvimento constituem um importante espaço de ampliação e consolidação da ciência, bem como de mecanismos de avaliações internas das instituições de ensino superior do país. 
O último capítulo que compõe o livro é de autoria de Marilda Schneider e intitula-se "Políticas de avaliação, prestação de contas e responsabilização (accountability) na educação superior brasileira". Neste texto, a autora aborda o Sistema Nacional de Avaliação da Educação Superior (Sinaes) e suas ferramentas de accountability para regulação da qualidade da educação superior brasileira. Afirma que o referido sistema é recente (2004), criado quase que concomitantemente com o da educação básica. A finalidade do Sinaes é a de avaliar instituições, cursos e estudantes da educação superior e prever a participação de discentes, docentes e profissionais técnicos administrativos. No entanto, a autora reforça que a regulação da qualidade recai sobre a avaliação realizada com os alunos mediante notas meramente classificatórias. Ao analisar as políticas de avaliação da educação superior, destaca que o Sinaes possui uma grande responsabilidade (accountability forte), com consequências de alto impacto social, já que os cursos que não atingem os indicadores são fechados ou rebaixados. Já na educação básica, há uma accountability fraca, pois as escolas que não atingem os índices não são penalizadas. Por fim, a autora critica a avaliação desenvolvida na educação superior brasileira ao compreender que, pelo fato de manter uma concepção normativa, distancia a universidade da autonomia e da produção científica significativa.

Após a explicitação dos textos, é possível perceber o cabedal de análises críticas que os autores apresentam em relação às avaliações em larga escala desenvolvidas em diversos países, abrangendo experiências dos continentes Americano, Europeu e Africano. Pelos relatos dos pesquisadores, é possível evidenciar que alguns contextos possuem sistemas de avaliação mais consolidados enquanto outros ainda se encontram em fase de implementação. Apesar desse fator, nos diferentes capítulos que compõem o livro, perpassam alguns pontos comuns, tais como: a avaliação da educação superior ganhou fôlego tanto de discussões/produções acadêmicas quanto em relação à criação e à implementação de sistemas de regulação após a expansão e a internacionalização desse nível de ensino, em especial, em países da América Latina, África e Portugal; há críticas quanto à forma como a qualidade de cursos e instituições tem sido verificada, pois avaliações em larga escala e censos de educação superior permitem verificar quantidade, mas não qualidade, haja vista que não analisam o contexto e as singularidades de cada instituição ou curso; há consenso de que a avaliação é um termo polissêmico, uma vez que gera tensões, conflitos. Além disso, há concordância entre os autores da necessidade de se avançar neste campo de estudo. 
Nesse sentido, para acadêmicos, estudiosos, pesquisadores e demais interessados que objetivam contribuir com o respectivo avanço, o livro "Avaliação do Ensino Superior: perspectivas mundiais" configura leitura extremamente significativa e produtiva, uma vez que, além de ser atual, aborda a mesma temática de diferentes ângulos, com diferentes experiências, em diferentes contextos, o que oportuniza ao leitor uma visão ampla sobre o assunto.

\section{Referências}

TAUCHEN, G.; FÁVERO, A. (Orgs.). Avaliação do ensino superior: perspectivas mundiais. Curitiba: CRV, 2017.

Recebido em: 15/10/2017

Aprovado para publicação em: 27/02/2018

Publicado em: 30/04/2019 